\title{
CHITOSAN ASSISTED SYNTHESIS OF MULTI-LAYERED ZINC CARBONATE HYDROXIDES FOR MASSIVE REMOVAL OF Cu${ }^{2+}$ FROM WATER
}

\author{
PEILI LIU ${ }^{a}$, YAO LII $I^{a}$ YEPING XU $U^{b}$ YE QING ${ }^{c}$, CHENGLIANG HAN ${ }^{a *}$ \\ a Department of Chemical and Material Engineering, Hefei University, Hefei 230601, P.R.C. \\ $b$ Department of Biological and Environmental Engineering, Hefei University, Hefei 230601, P.R.C. \\ c Key Laboratory of Novel Thin-film Solar Cells, Institute of Applied Technology, Chinese Academy of Sciences, Hefei, Anhui, 230031, P. R.C.
}

\begin{abstract}
In this paper, the zinc carbonate hydroxide $\left(\mathrm{Zn}_{5}(\mathrm{OH})_{6}\left(\mathrm{CO}_{2}\right)_{2}, \mathrm{ZCHO}\right)$ was prepared by a facile hydrothermal method assisted chitosan $(\mathrm{CS})$. The as-prepared product was characterized by X-ray diffraction (XRD), scanning electron microscopy (SEM) and thermogravimetric analysis (TG). Results indicated that every micro-sized ZCHO particle had a multi-layered structure and was composed of many ZCHO nanoplates. The used CS played the role of the template in the formation of well multi-layered ZCHO particles. TG measurements had further indicated that the remained content of CS in the as-prepared ZCHO powders was about $8 \mathrm{Wt} . \%$. The adsorption isotherm results showed that the $\mathrm{ZCHO}$ powders with $\mathrm{CS}$ exhibited massive removal of $\mathrm{Cu}^{2+}$ from aqueous solution at room temperature. The equilibrium adsorption was well described by the Freundlich isotherm model. Based on the above experimental results, the possible removal mechanism of $\mathrm{Cu}^{2+}$ by the multi-layered $\mathrm{ZCHO}$ was proposed.
\end{abstract}

Keywords: Zinc carbonate hydroxide; Chitosan; Freundlich model; Removal of $\mathrm{Cu}^{2+}$

\section{INTRODUCTION}

Water pollution has drawn a high attention at the present time, especially, heavy metal pollution such as $\mathrm{Pb}^{2+}, \mathrm{Cu}^{2+}, \mathrm{Co}^{2+}, \mathrm{Cd}^{2+}$ and so on, is one of the prevalent environmental problems and produces adverse effects on human health and ecosystem $[1,2]$. Among these heavy metal ions ions, $\mathrm{Cu}^{2+}$ is considered to be one of the most hazardous because it can be accumulated in the human organs by food chain[3,4]. Thus, the removal of heavy metals from wastewater has attracted particular attention.

Various techniques such as chemical precipitation[5], ion exchange[6,7], membrane separation[8], electro coagulation and adsorption[9-11] have been commonly utilized to remove heavy metal ions from discharged wastewater. However, parts of these techniques have drawbacks, for instance, creating toxic by-production resulting from chemical precipitation. Additionally, the method of ion exchange to deal with heavy metal ions was usually much expensive and had the ion concentration limit. Among these approaches, adsorption was highly preferred on account of its reliability, economy, flexible, fast kinetics and easy operations[12].To date, many novel adsorbents such as nanomaterials, ion imprinted materials, mesoporous materials, carbon nanotubes and magnetic nanoparticles have been employed to remove heavy metal ions. Micro/nanosized materials are the just kind of new adsorbents and have gained much attention. Because of their distinct chemical, physical and biological properties and high stability, the micro/nano-sized materials are able to adsorb metal ions with high adsorption capacity $[13,14]$.

The biopolymers such as chitosan (CS) and chitin are one of the emerging adsorbents for the removal of dyes and heavy metal ions $[15,16]$. To improve the mechanical properties and adsorption capacity of CS, numerous studies have been devoted to the chemical modification of CS by homogeneous or heterogeneous cross-linking agents [17, 18]. Furthermore, CS-based composites with enhanced mechanical and adsorption properties have also been reported [19-21].

In the present work, the zinc carbonate hydroxide $\left(\mathrm{Zn}_{5}(\mathrm{OH}){ }_{6}\left(\mathrm{CO}_{2}\right)_{2}\right.$, $\mathrm{ZCHO}$ ) with chitosan (CS) was prepared and characterized using different techniques such as by X-ray diffraction (XRD), scanning electron microscopy (SEM) and thermogravimetric analysis (TG).The adsorption ability of $\mathrm{Cu}^{2+}$ by as-prepared powders was investigated at room temperature. To the best of our knowledge, removal of copper ions from solution using ZCHO with CS is new. In addition, comparing with some other nanoadsorbents, the micro/nano-sized $\mathrm{ZCHO}$ was found to be stable and easily precipitated. Therefore, the problem of separation techniques with high-cost can be solved. At the same time, the micro/nano-sized ZCHO with CS adsorbent can be scale up economically due to CS easily extracted from chitin exist in some hard shell animals' skins.

\section{EXPERIMENT SECTION}

2.1. Synthesis and characterization

All the used chemicals were analytical grade and without further purification. In a typical process, $0.15 \mathrm{~g}$ of chitosan (CS) was dissolved in acetic acid aqueous solution $(150 \mathrm{~mL}, \sim 5 \mathrm{Wt}$. \%) with vigorous stirring at room temperature for 30 minutes to form a chitosan-acetic acid (CS-HAC) colloidal solution. After that, $2 \mathrm{~mL}$ CS-HAC colloidal solution, $40 \mathrm{~mL} 0.2 \mathrm{~mol} / \mathrm{L} \mathrm{Na}_{2} \mathrm{CO}_{3}$ and $40 \mathrm{~mL} 0.2 \mathrm{~mol} / \mathrm{L} \mathrm{ZnCl}_{2}$ aqueous solutions were transferred into a beaker, respectively. The mixture solution was stirred for $1 \mathrm{~h}$ at room temperature. Finally, the resulting solution was transferred into a $100 \mathrm{~mL}$ Teflon-lined stainless-steel autoclave and heated at $140^{\circ} \mathrm{C}$ for $8 \mathrm{~h}$, followed by cooling to temperature naturally. The final product was separated and washed with deionized water and absolute ethanol for several times and dried at $80^{\circ} \mathrm{C}$ in oven for $12 \mathrm{~h}$ and characterized by X-ray diffraction (XRD), scanning electron microscopy (SEM, SU-8010) and thermogravimetric analyzer (TG), respectively.

1.2. Batch adsorption experiments

For thermodynamic study, $0.5 \mathrm{~g}$ adsorbent was introduced into beaker flasks containing $100 \mathrm{~mL}$ solutions with various concentration of $\mathrm{Cu}^{2+}(50$ $600 \mathrm{mg} / \mathrm{L}, \mathrm{pH}=6.5$ ). The flasks were agitated at $160 \mathrm{rpm}$ in a thermostatic shaker maintained at $25^{\circ} \mathrm{C}$. After adsorption, the mixture was separated by centrifugation and the concentration of $\mathrm{Cu}^{2+}$ was measured by hydride generation atomic absorption spectrophotometry (ICP-AES). The amount of equilibrium adsorption $\left(\mathrm{q}_{\mathrm{e}}, \mathrm{mg} / \mathrm{g}\right)$ was calculated from Eq. (1):

$$
\mathrm{q}_{\mathrm{e}}=\frac{\left(\mathrm{C}_{0}-\mathrm{C}_{\mathrm{e}}\right) \mathrm{V}}{\mathrm{m}}
$$

Where $\mathrm{C}_{0}(\mathrm{mg} / \mathrm{L})$ stands for the initial concentration of copper, and $\mathrm{C}_{\mathrm{e}}$ $(\mathrm{mg} / \mathrm{L})$ is the liquid-phase concentration at equilibrium. $\mathrm{V}(\mathrm{L})$ is the volume of solution, and $\mathrm{m}(\mathrm{g})$ is the mass of used sorbents.

\section{RESULTS AND DISCUSSION}




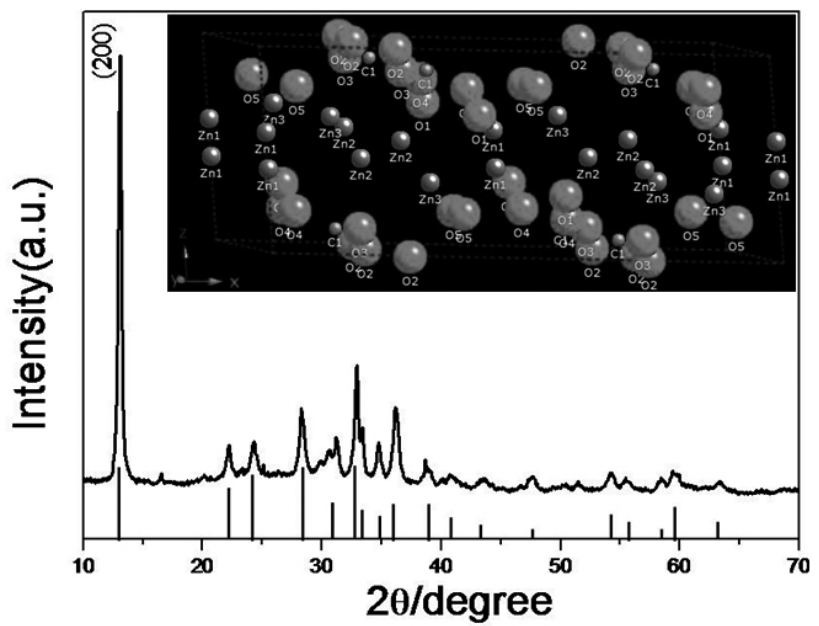

Figure 1. XRD pattern of the as-prepared product and its standard pattern.

XRD spectrum of the as-prepared product with CS additive was presented in Fig. 1. From the XRD spectrum it was found that the product was well crystallized. The major peaks correspond to $\mathrm{Zn}_{5}\left(\mathrm{CO}_{3}\right)_{2}(\mathrm{OH})_{6}$ (JCPDS 19-1458, zinc carbonate hydroxide, ZCHO).Very similar XRD spectra was also obtained for the sample prepared without any CS additive (not presented in the paper).
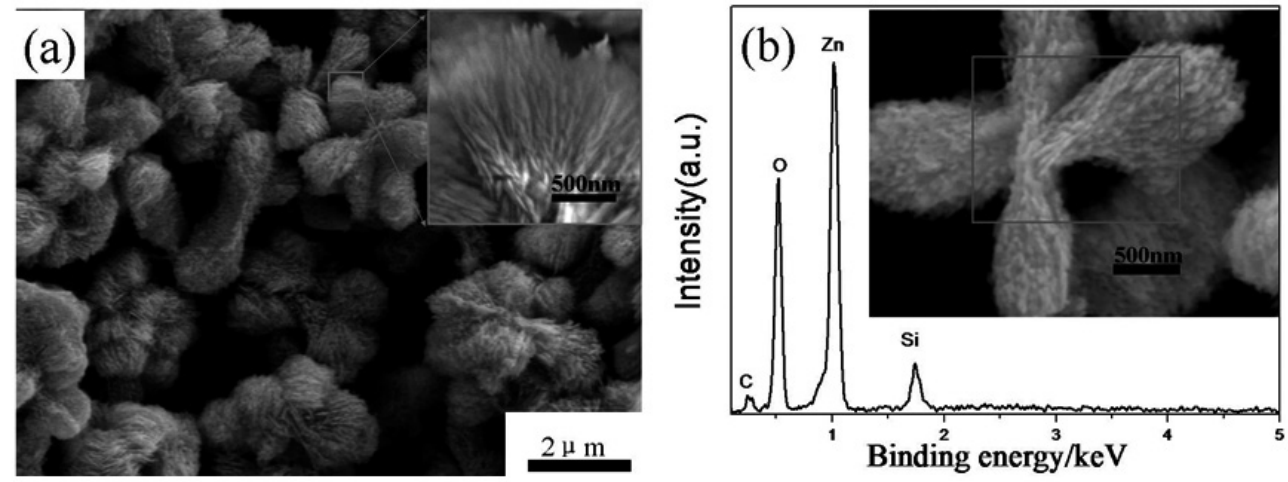

Figure 2. (a)FE-SEM micrograph of a sample prepared with addition of CS (25 mg/L) and the corresponding EDS spectrum (b).

Fig. 2(a) shows the surface morphology and particle size of the hydrothermally synthesized ZCHO powders. It can be seen that the individual ZCHO particle generally exhibits an irregular shape with particle size ranging from 2-6 $\mu \mathrm{m}$. Each ZCHO particle has a multi-layered structure which means that every micro-sized ZCHO particle is composed of many nanoplates (seen from the inset in Fig.2 (a)). Fig.2 (b) shows the chemical composition of the sample on a Si wafer marked by a purple curve in the inset of Fig.2b. The elements of $\mathrm{Zn}, \mathrm{O}$ and $\mathrm{C}$ are found in the sample which belongs to ZCHO particle. Overall, it is concluded that the as-obtained ZCHO particle has a multi-layered structure.

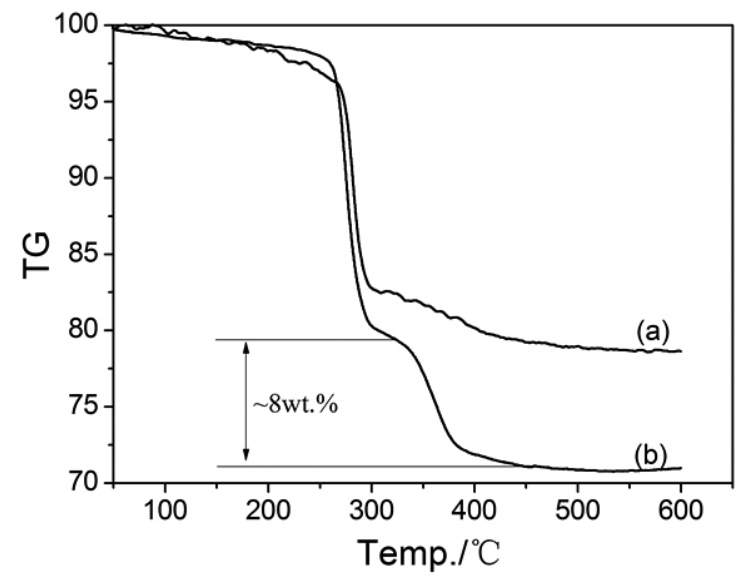

Figure 3. Thermogravimetric analysis of ZCHO powders obtained from different concentration of CS ((a) $0 \mathrm{mg} / \mathrm{L}$, (b) $25 \mathrm{mg} / \mathrm{L}$ )

Fig. 3 shows the TG curves of the ZCHO powders synthesized without and with CS addition, respectively. As expected, Fig.3a shows the normal singlestep decomposition process between approximately $180^{\circ} \mathrm{C}$ and $350^{\circ} \mathrm{C}$ in which $\mathrm{Zn}_{5}(\mathrm{OH})_{6}(\mathrm{CO})_{2}$ decomposes to form $\mathrm{ZnO}$ with the release of $\mathrm{CO}_{2}$ and $\mathrm{H}_{2} \mathrm{O}$. In comparison, Fig. $3 \mathrm{~b}$ exhibits a typical two-step decomposition process in the range of $180^{\circ} \mathrm{C} \sim 400^{\circ} \mathrm{C}$. There is a major weight change event from $300^{\circ} \mathrm{C}$ to $400^{\circ} \mathrm{C}$, which should be mainly attributed to the decomposition of CS in the multi-layered ZCHO powders. The percentage weight loss of CS was about $8 \mathrm{Wt}$.\% which is comparable to the calculated value without CS addition from Fig.3a. 

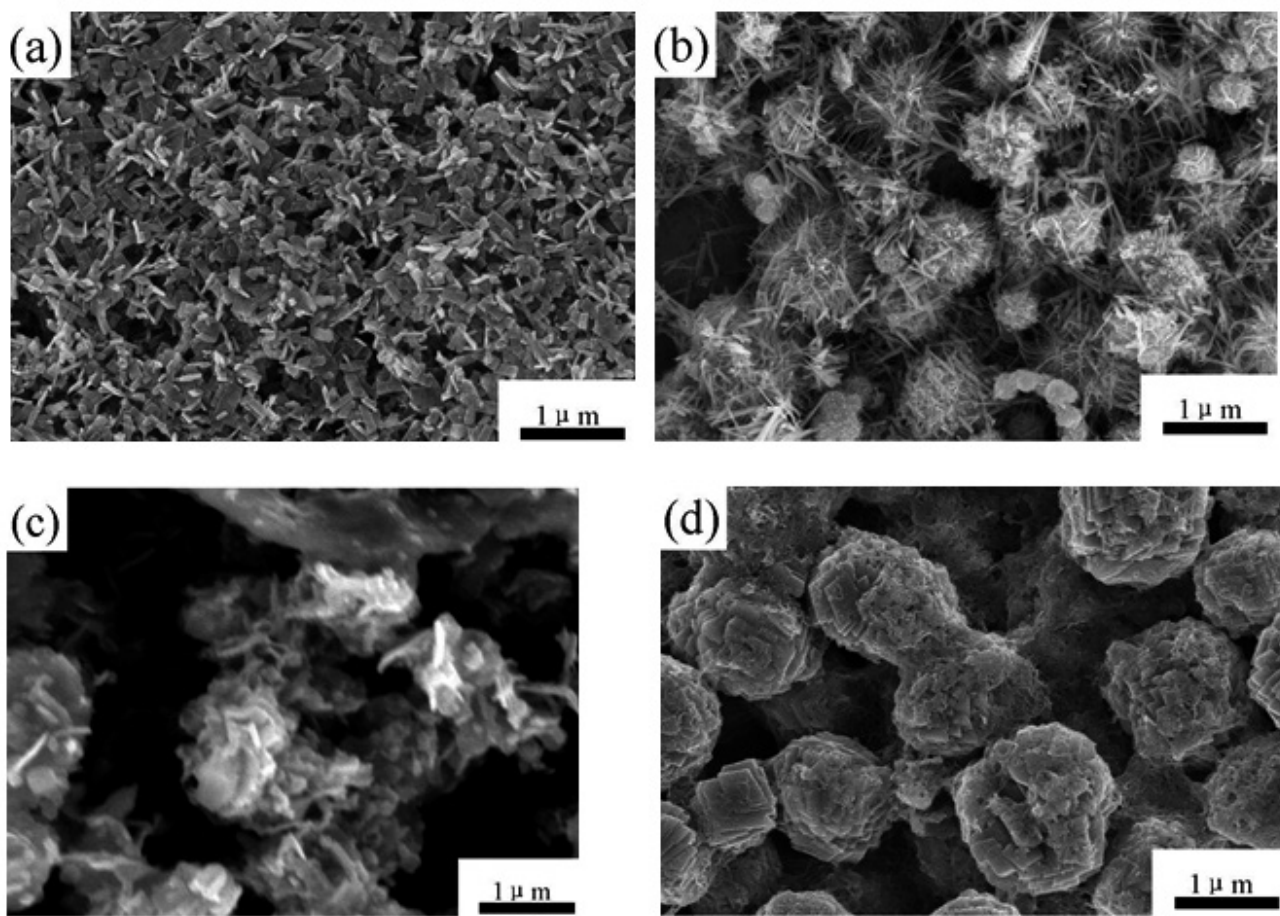

Figure 4. Influence of concentration of CS on the morphology of products ((a) $0 \mathrm{mg} / \mathrm{L}$, (b) $15 \mathrm{mg} / \mathrm{L}$, (c) $75 \mathrm{mg} / \mathrm{L}$ and (d) $100 \mathrm{mg} / \mathrm{L}$ )

It has been demonstrated that the content of CS in the solution played an in-displaceable role in the formation of the multi-layered ZCHO adsorbents. Fig.4 shows the morphological evolution of the final products with CS content in the precursor solution varied from $0 \mathrm{~g} / \mathrm{L}$ to $100 \mathrm{mg} / \mathrm{L}$. Without addition of CS, only nearly plate-shaped ZCHO nanoparticles were formed (Fig. 4a). Addition of small amount of CS (less than $25 \mathrm{mg} / \mathrm{L}$ ) leads to the mixture of ZCHO nanoplates and multi-layered spherical particles. When CS was added in a proper content $(25-75 \mathrm{mg} / \mathrm{L})$, the multi-layered ZCHO with high quality will be obtained, as shown in Fig.2a. But if CS was added too much $(>75 \mathrm{mg} / \mathrm{L}$ ), the aggregated ZCHO particle was only obtained (seen from Fig.4d).

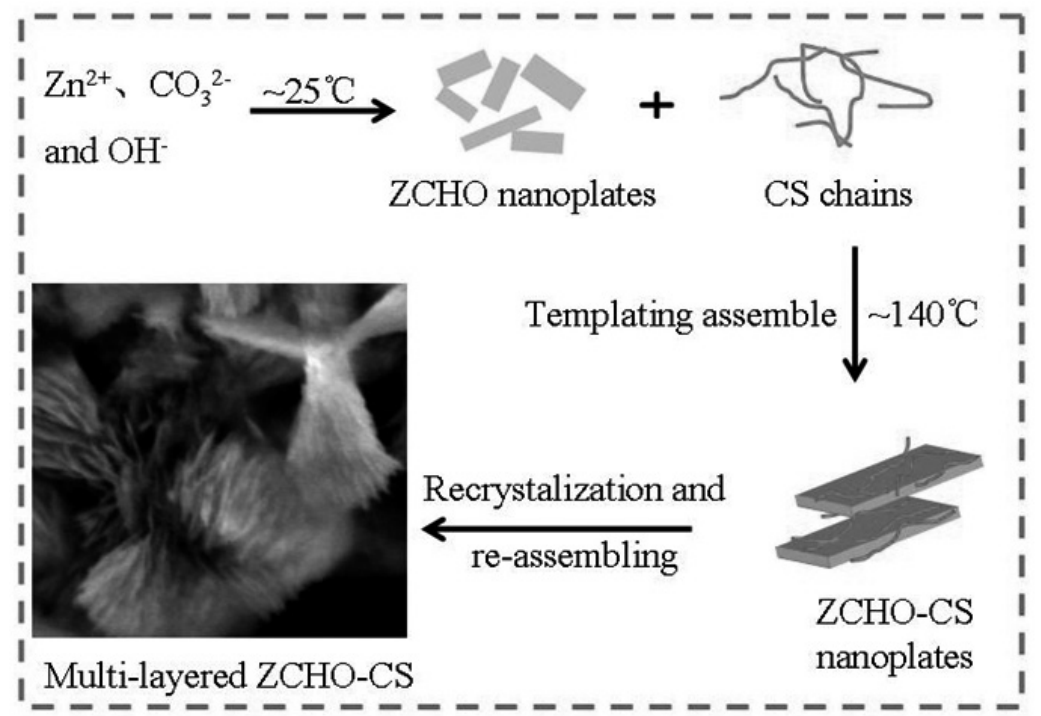

Figure 5. Schematic formation progress of the multi-layered ZCHO-CS particle

Based on the above results, the formation progress of multi-layered ZCHO particle can be regarded as following three steps which has shown in Fig.5. First of all, the ZCHO nanoplates with dispersing CS chains precursors will be obtained at room temperature. Secondly, the above precursors will be immediately assembled hydrothermally to form ZCHO-CS nanoplates at $140^{\circ} \mathrm{C}$ for $8 \mathrm{~h}$. Finally, the ZCHO-CS nanoplates will be transformed into multi-layered ZCHO-CS particles by self-reassembling and recrystalization in order to reduce the energy of the reaction system. It is noted that the shape of precursors and the content of CS play important roles in the formation of the multi-layered ZCHO product. 

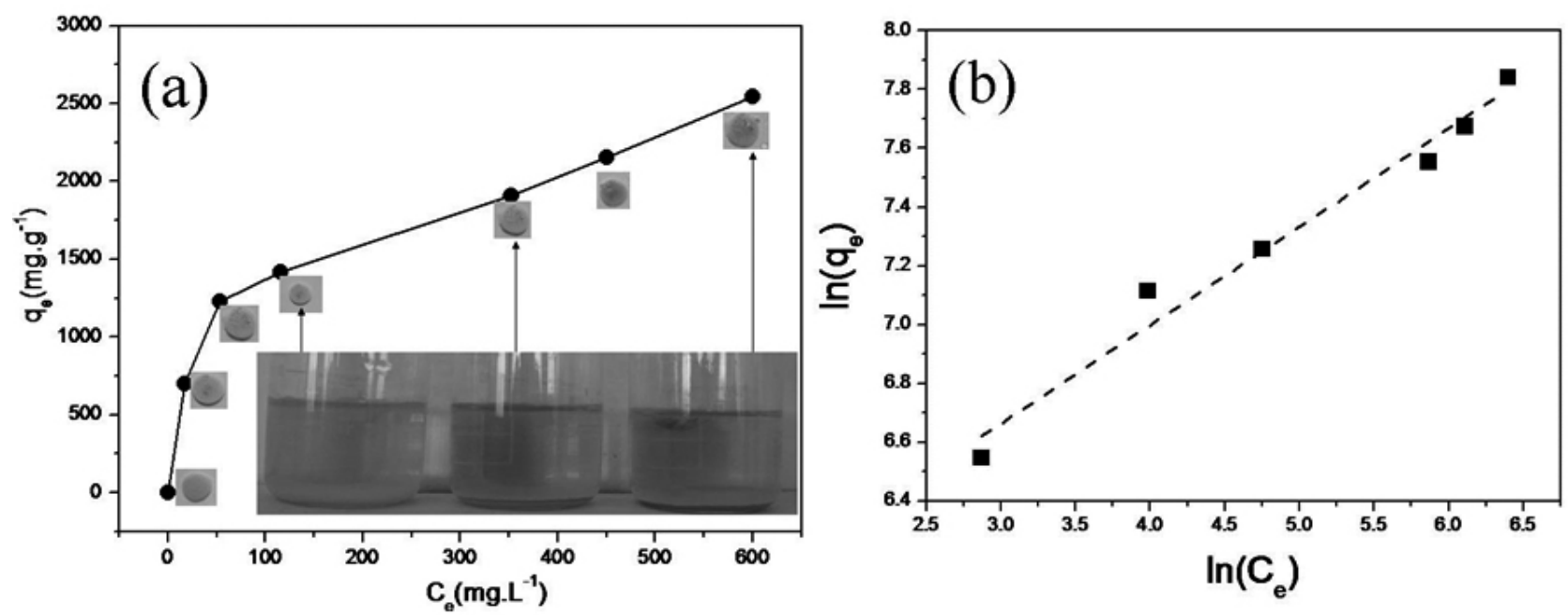

Figure 6. (a) Adsorption isotherm of $\mathrm{Cu}^{2+}$ onto $\mathrm{ZCHO}$ and (b) corresponding fitting of the isotherm data with Freundlich model (Experimental conditions: temperature: $25^{\circ} \mathrm{C}$, adsorbent dose: $0.5 \mathrm{~g} / 100 \mathrm{~mL}$ ).

Adsorption isotherm is an important part of this study, as it can provide some using information about the adsorption capacity as well as the surface properties and affinity of the applied adsorbents, providing a better understanding on how an adsorption system can be improved [22]. To further confirm $\mathrm{Cu}^{2+}$ removal behavior of ZCHO powders, the batch experiments with different initial concentration ranging from 50 to $600 \mathrm{mg} / \mathrm{L}$ were carried out. Freundlich isotherm (Eq. (2)) [23] was used to fit the experimental data.

$$
\mathrm{q}_{\mathrm{e}}=\mathrm{K}_{\mathrm{F}} \mathrm{C}_{\mathrm{e}}^{1 / \mathrm{n}}
$$

Where $\mathrm{K}_{\mathrm{F}}$ is a measure of adsorption capacity and $\mathrm{n}$ stands for the heterogeneity. The linear form was expressed as followed (Eq. (3)) and the fitting result was shown in Fig.6b:

$$
\ln \left(\mathrm{q}_{\mathrm{e}}\right)=\ln \left(\mathrm{K}_{\mathrm{F}}\right)+\frac{1}{n} \ln (\mathrm{C} e)
$$

From Fig.6b, it can be found that the Freundlich model well matches the tested adsorption data fitting with high correlation coefficient more than 0.97 , which means a multi-layered adsorption on heterogeneous surfaces of the ZCHO-CS adsorbents with chemical nature happened between the adsorbents and $\mathrm{Cu}^{2+}$. Comparison of our results with commercial adsorbents such as modified chitosan and chitosan-coated magnetic nanoparticles shows that the ZCHO-CS adsorbent has many advantages. A very high adsorption capacity was observed for the ZCHO-CS adsorbent with respect to the literatures [24, 25]. Additionally, the prepared adsorbent could be precipitated easily from aqueous solutions. All of these advantages make ZCHO-CS become a novel adsorbent for removal of $\mathrm{Cu}^{2+}$ from water.

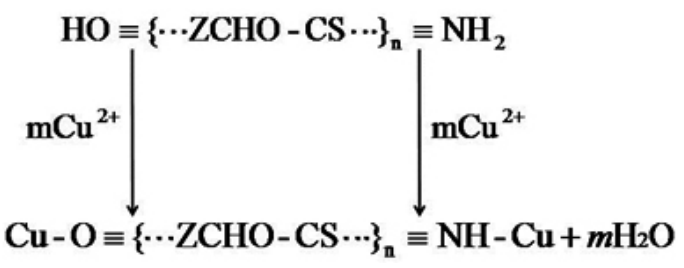

Based on the above data, a possible removal mechanism of $\mathrm{Cu}^{2+}$ ions for the ZCHO-CS powders can be proposed as follows: the hydroxyl groups($\mathrm{OH})$ and amino groups $\left(-\mathrm{NH}_{2}\right)$ on the interface of multi-layered ZCHO-CS particles ,as adsorption sites, become more available and enhance the CHO-CS adsorption ability. Furthermore, accesses to the adsorption sites inside interface becomes easier because of surface hydrogen bonds destruction and reaction with $\mathrm{Cu}^{2+}$ to form the complex-Cu immobilized on the ZCHO-CS adsorbents and precipitated from solution in the end (seen from reaction (4).

\section{CONCLUSIONS}

Zinc carbonate hydroxide powders have been produced by hydrothermal process. XRD data revealed the formation of $\mathrm{Zn}_{5}(\mathrm{OH})_{6}\left(\mathrm{CO}_{3}\right)_{2}$ crystal structure SEM images showed that the synthesized $\mathrm{Zn}_{5}(\mathrm{OH})_{6}\left(\mathrm{CO}_{3}\right)_{2}$ generally exhibit homogeneous particle size in the range of 2-4 $\mu \mathrm{m}$. There is significant change observed in size and morphology of the particles synthesized with different content of CS addition. TG analysis showed the typical two-step decomposition process between approximately $300{ }^{\circ} \mathrm{C}$ and $400{ }^{\circ} \mathrm{C}$ in which $\mathrm{Zn}_{5}(\mathrm{OH})_{6}\left(\mathrm{CO}_{3}\right)_{2}$ with $\mathrm{CS}$ decomposes to form $\mathrm{ZnO}$ with the release of $\mathrm{CO}_{2}$ and $\mathrm{H}_{2} \mathrm{O}$. The calculated value of percentage weight loss of CS was about $8 \mathrm{Wt} . \%$. The adsorption isotherm results indicated that the as-prepared $\mathrm{Zn}_{5}(\mathrm{OH})_{6}\left(\mathrm{CO}_{3}\right)_{2}$ adsorbent exhibited massive removal of $\mathrm{Cu}^{2+}$ from aqueous solution at room temperature. The equilibrium adsorption was well described by the Freundlich isotherm model.

\section{ACKNOWLEDGEMENT}

This study was funded by the Natural Science Foundation of Education Department of Anhui Province (Grant No. KJ2015A170) and Natural Science Foundation of Hefei University (Grant No. 16ZR10ZDA, 8ZR).

\section{REFERENCES}

[1] Meng Yuying, Chen Deyang, Sun Yitao, Jiao Dongling, Zeng Dechang, Liu Zhongwu, Appl.Surf. Sci., 324,745 (2015).

[2] Karthik Rathinam, Meenakshi Sankaran, Chem. Eng. J., 263,168(2015).

[3] Wen Yuezhong, Ma Jianqing, Chen Jie, Shen Chensi, Li Hong, Liu Weiping, Chem. Eng. J., 259, 372(2015).

[4] Sun Qing, Li Hui, Niu Baojun, Hu Xiaolong, Xu Chunhong, Zheng Shuilin, Procedia Eng., 102, 1935 (2015).

[5] Brijesh Shah, U. Chudasama, J. Hazard. Mater. 276, 138(2014).

[6] Li Jian-Rong, Wang Xu, Yuan Baoling, Fu Ming-Lai, J .Molecular Liquids, 200,205(2014).

[7] R.N. Ntimbani, G.S. Simate, S. Ndlovu, J. Environ. Chem. Eng., 3, 1258(2015)

[8] Takht Ravanchi Maryam, Kaghazchi Tahereh, K. Ali., Desalination, 235 , 199 (2009).

[9] Wongsakulphasatch Suwimol, Kiatkittipong Worapon, Saiswat Janekit, Oonkhanond Bovornlak, Striolo Alberto, Assabumrungrat Suttichai, Inorg.Chem.Comm., 46, 301 (2014).

[10] Dong Ying-bo, Lin Hai, Transactions of Nonferrous Metals Society of 
China, 25, 991(2015).

[11] Jaime Pizarro, Ximena Castillo, Sebastián Jara, Claudia Ortiz, Patricio Navarro, Héctor Cid, Héctor Rioseco, Daniel Barros, N. Belzile, Fuel, 156, 96(2015).

[12] Zhao Lianqin, Yu Baowei, Xue Fumin, Xie Jingru, Zhang Xiaoliang, Wu Ruihan, Wang Ruijue, Hu Zhiyan, Yang Sheng-Tao, Luo Jianbin, J. Hazard. Mater. 286, 449 (2015).

[13] Yuying Meng, Deyang Chen, Yitao Sun, Dongling Jiao, Dechang Zeng, Zhongwu Liu, Appl. Surf. Sci., 324, 745 (2015).

[14] Aaron P. Mosier, Jason Behnke, Eileen T. Jin, Nathaniel C. Cady, J. Environ. Manag. 160, 67(2015).

[15] S. Nasirimoghaddam, S. Zeinali, S. Sabbaghi, J. Industr. Eng.Chem., 27, 79 (2015).

[16] Xiaoyong Zhang, Qiang Huang, Meiying Liu, Jianwen Tian, Guangjian Zeng,Zhen Li, Ke Wang, Qinsong Zhang, Qing Wan, Fengjie Deng, Yen Wei, Appl.Surf. Sci., 343, 19 (2015).

[17] Nadia G. Kandile, Hemat M. Mohamed, Mansoura I. Mohamed, Inter. J.
Biolog.Macromolec, 72, 110 (2015)

[18] Maria Valentina Dinu, Ecaterina Stela Dragan, Chem. Eng. $J ., 160,157(2010)$.

[19] Mini Namdeo, S.K. Bajpai, Colloids. Surf. A: Physicochemical and Engineering Aspects, 320, 161 (2008).

[20] Yankun Zhan, Likun Pan, Chunyang Nie, Haibo Li, Zhuo Sun, J. Alloy. Compd., 509, 5667(2011).

[21] Xiaoli Li, Yanfeng Li, Sidi Zhang, Zhengfang Ye, Chem. Eng. J. 183, 88(2012).

[22] M.A. Shaker, J. Taiwan Instit.Chem.Eng. 0, 1 (2015).

[23] Zhang Xiaoyong, Huang Qiang, Liu Meiying, Tian Jianwen, Zeng Guangjian, Li Zhen, Wang Ke, Zhang Qinsong, Wan Qing, Deng Fengjie, Wei Yen, Appl. Surf. Sci., 343, 19(2015).

[24] B. Kannamba, K. Laxma Reddy, B.V. AppaRao, J Hazard. Mater., 175, 939(2010).

[25] Yu-Ting Zhou, Hua-Li Nie, Christopher Branford-White, Zhi-Yan He, Li-Min Zhu, J. Colloid .Interf. Sci., 330, 29 (2009). 